\title{
The Assessment Study of Entered Biological Agents Circulation Based on Supply Chain Risk Conduction Model
}

\author{
Li Ma \\ School of Economics and Management \\ Beijing Jiaotong University \\ Beijing, China \\ School of Management \\ Hebei United University \\ Hebei, China \\ mali.f116@gmail.com \\ Yihong $\mathrm{Ru}$ \\ School of Economics and Management \\ Beijing Jiaotong University \\ Beijing, China \\ yhru@bjtu.edu.cn
}

\author{
Qi Zhang \\ School of Economics and Management \\ Beijing Jiaotong University \\ Beijing, China \\ zhangqi2106602@126.com
}

\begin{abstract}
As the rapid development of global biochemical industry, biological agents which situate on the highest level play a significant role in biological science research. However, there are many kinds of biological agents having strong infectivity, which may bring unpredictable biosecurity risks in the circulation. This paper applies supply chain risk management theory to set up a model for assessment of entered biological agents risks. Consider both the suppliers abroad and domestic demanding sides, the study carries out risk conduction paths derivation and risk assessment during the circulation process, which intends to find out the key points of supervision and ensure the entry regulation safety of biological agents. The magnitude of risk conduction path is able to be calculated on the basis of the probability of risk occurrence and consequence of risks and the essential problems of circulation regulation which deserves more attention have already been put forward. Therefore,the conclusion of the paper is to put high emphasis on the pivotal link and path.
\end{abstract}

Keywords- risk conduction model; supply chain; biologial agent; risk management;import

\section{INTRODUCTION}

From the perspective of supply chain management, there are biological risks for entered biological reagent during the process of production, circulation and using from biochemical reagents suppliers abroad to domestic demand side. It is different from ordinary management of supply chain, as the risk management of entered biological reagent involves biological safety, and it belongs to a special kind of risk management of supply chain in that it contains the regulatory approval chain of the government which includes the process of professional approval and the inspection on the spot before the entry.

\section{LITERATURE REVIEW}

\section{A. Studies on Risk Management of Supply Chain}

In the past few years, numerous scholars have made a lot of researched on the risk management of supply chain. Hallikas $(2002,2004)$ studied risk analysis and assessment in the network environment, the process of network risk management and indicated what kind of risk occurred in network collaboration and how to deal with risk management in network collaboration. Crock ford (1986) put forward that the consequences of risk event can be measured by the possibility of the risk occurrence and the severity of the potential loss. Williams (1996) believed that it is generally accepted to perform risk assessment from the perspectives of probability (possibility) and effect (consequence). Mitchell (1995) though that the risk can be measured by the possibility of the risk occurrence multiplied by the severity of the consequences of risk (loss probability model), that is Risk $=P($ Loss $) \times$ Loss , Risk represents the degree of risk, $\mathrm{P}$ represents the probability or the possibility of the risk occurrence and Loss represents the consequences of risk.

\section{B. Studies on Risk Conduction}

Researches on risk conduction both at home and abroad mainly focus on the correlation between financial risk and crisis. Balg Taimu and Goldfajn Ilan (1998) carried out a study on the risk conduction of financial crisis in the East Asia. Kaminsky and Reinhart (1999) made a research on the transmitting of credit risk between different countries. Cui Yi and other scholars studied the conduction mechanism of micro risk of enterprises and macro financial crisis. Deng Mingran and other scholars discussed steady conduction and unsteady conduction and 
the definition of supply chain risk conduction, the path and the carrier. Ye Jianmu and others analyzed the characteristics of the supply chain risk conduction and the internal causes of risk conduction. However, few articles can be found to display the process of conduction, measurement method and the degree of effects through the quantitative analysis.

\section{Studies on Biomedical Risk Management}

Studies on biomedical risk management primarily focus on laboratory biological safety risk, the risk of production and quality control on biological products and safety assessment of transgenic organisms. Li Sa, Wang Qinggai (2013) made a research on biological safety laboratory construction and safety management system; Chen Baowen (2010) investigated biological safety risk of the production and quality control on biological products; Freese W. and Schubert D. (2004) analyzed genetically modified food safety; Myhr A I and Traavik T. (2002) issued scientific uncertainty and omitted research in the context of GMO use and release.

\section{THE PROCESS OF MODEL EstABLISHMENT}

\section{A. Variable Definition}

The set of risk factors:

$$
R=\left\{R_{i} \mid S\left(R_{i}\right), \operatorname{Loss}\left(R_{i}\right), P\left(R_{i}\right), N\left(R_{i}\right), \operatorname{Risk}\left(R_{i}\right)\right\}
$$

$R_{i}$ represents risk factors; $S\left(R_{i}\right)$ represents the subjects; $\operatorname{Loss}\left(R_{i}\right)$ represents the expectation of loss to the subjects once $R_{i}$ occurs; $P\left(R_{i}\right)$ represents the risk probability of $R_{i} ; N\left(R_{i}\right)$ represents the number of risk factors affected by $R_{i} ; \operatorname{Risk}\left(R_{i}\right)$ represents the expectation of loss on the whole supply chain caused by $R_{i}$.

$P_{R_{i} \rightarrow R_{j}}$ is the probability of $R_{j}$ conducted by the risk factor $R_{i}$; father $(R i)$ is the father set of risk factors affecting the risk factor $R_{i}$; $\operatorname{son}\left(R_{i}\right)$ is the subset of risk factors affected by $R_{i}$; $\operatorname{count}(R)$ is the number of all risk factors concluded in the set of $R$.

All the factors affected (conducted) by $R_{i}$ are the children of the first risk factors; all the effects (conduction) affecting $R_{i}$ are the ancestor of risk factors.

\section{B. The Measurement of Risk}

$$
\text { Risk }=P(\text { Loss }) \times \text { Loss }
$$

Risk represents the magnitude of risks; $\mathrm{P}$ represents the probability or possibility of risk occurrence, Loss represents the consequence of risks.

\section{The Polymerization Calculation of Risk Conduction Receptor}

In the process of risk conduction in supply chain, risks with all kinds of different natures are complex and coexisting, and a variety of risk conduction often occurs at the same time. The study assumes that risk coupling does not occur in the process of conduction, and the effect of risk conduction should reflect on the occurrence probability of risk conduction, which means that the occurrence of a risk factor of increases the occurrence probability of the other risk factor. As shown in Fig .1,supposing $\mathrm{n}$ risk factors can conduct risk probability to $R b$, and the risk probability of $R_{1}, R_{2}, \ldots, R_{n}$ are $P_{1}$, $P_{2}, \ldots, P_{n}$ respectively, and the intensity of $R b$ are $\frac{P_{R 1 \rightarrow R b}}{n}, \frac{P_{R 2 \rightarrow R b}}{n}, \ldots, \frac{P_{R n \rightarrow R b}}{n}$ (the probability of $R b$ conducted by $\left.R_{1} 、 R_{2} 、 \ldots 、 R_{n}\right)$.

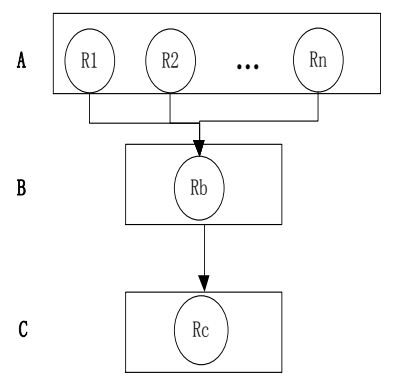

Figure 1. The network structure of supply chain

Based on the hypothesis, risk polymerization formula of arithmetic average is presented:

$$
P_{R b}=\frac{P_{R 1 \rightarrow R b} \times P_{1+} P_{R 2 \rightarrow R b} \times P_{2+\ldots+} P_{R n \rightarrow R b} \times P_{n}}{n}, 0 \leq P_{R b} \leq 1
$$

\section{The Calculation of $P_{R_{i}} \rightarrow R_{j}$ Conduction Probability}

The probability of the risk can be derived through the statistical analysis of historical data, but $P_{R 1 \rightarrow R b}$, $P_{R 2 \rightarrow R b}, \ldots, \quad P_{R n \rightarrow R b}$ are obtained by scores from experted decisions. For example, the first expert considers that the value of $P_{R 1 \rightarrow R b}$ is $q_{1}$, and the second expert thinks the value of $P_{R 1 \rightarrow R b}$ is $q_{2}$, supposing the $m$ expert regards the value of $P_{R 1 \rightarrow R b}$ is $q_{m}$, the value of $P_{R 1 \rightarrow R b}$ is:

$$
P_{R 1 \rightarrow R b}=\frac{1}{f} \sum_{m=1}^{f} q_{m}
$$

Therefore, the value of $P_{R 2} \rightarrow R b, \ldots, \quad P_{R n \rightarrow R b}$ can be calculated in the same way.

\section{E. The Solutions to the Occurrence Probability of All Risk Factors}

According to (2), the solution to the occurrence probability of $R_{i}$ is:

$$
P\left(R_{i}\right)=\sum_{\alpha=1}^{n} \frac{P\left(\text { father }\left(R_{i}\right)_{\alpha}\right) \times P_{\text {father }(R i)_{\alpha} \rightarrow R i}}{\text { count }\left(\text { father }\left(R_{i}\right)\right)}
$$

F. The Solution to Loss Expectation of Risk Factors to the Subjects and the Whole Supply Chain

$$
P^{\prime}\left(\operatorname{son}\left(R_{i}\right) \alpha\right)=\frac{P(R i) \times P_{r i} \rightarrow \operatorname{son}(R i) \alpha}{\operatorname{count}\left(\operatorname{father}\left(\operatorname{son}\left(R_{i}\right) \alpha\right)\right)}
$$

The risk of children risk factors can be conducted from father risk factors, so the probability $P^{\prime}\left(\operatorname{son}\left(R_{i}\right) \alpha\right)$ of $\alpha$ children risk factor conducted by $R_{i}$ can be calculated according to (5).

$$
\operatorname{Risk}\left(\operatorname{son}\left(R_{i}\right) \alpha\right)=P^{\prime}\left(\operatorname{son}\left(R_{i}\right) \alpha\right) \times \operatorname{Loss}\left(\operatorname{son}\left(R_{i}\right) \alpha\right)
$$


The degree of loss expectation of children risk factors conducted by $R_{i}$ can be calculated based on (6).

$$
\operatorname{Risk}(r i)=\sum_{k=1}^{N} P^{\prime}\left(A\left(R_{i}\right) \mathrm{k}\right) \times \operatorname{Loss}\left(A\left(R_{i}\right) \mathrm{k}\right)
$$

Supposing $A\left(R_{i}\right)$ is the set of $\mathrm{N}$ children risk factor of $R_{i}, \operatorname{Risk}(r i)$ is bound to get according to (7).

\section{RISK ASSESSMENT OF ENTERED BIOLOGICAL REAGENTS}

\section{A. Risk Network}

There are five subjects in the risk network of biological reagent circulation, which are foreign biological reagent suppliers, domestic demand side of biological reagent, health management department, department of quality supervision and customhouse. Firstly, people need to identify those five subjects and then get to know the risk transmission path and the structure of risk network, as the Fig .2 shown below:

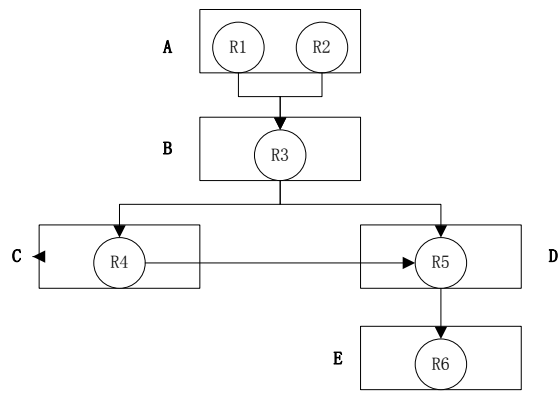

Figure 2. The risk network diagram of biological reagent circulation

TABLE I. SPECIFICATION TABLE OF RISK FACTORS AND SUBJECTS

\begin{tabular}{|c|c|c|c|c|}
\hline $\begin{array}{c}\text { Risk } \\
\text { factor( }(R)\end{array}$ & $\begin{array}{l}\text { Name of } \\
\text { risk factor }\end{array}$ & loss & Subject & $\begin{array}{c}\text { Name of the } \\
\text { subject }\end{array}$ \\
\hline R1 & Quality risk & 80 & \multirow[b]{2}{*}{ A } & \multirow{2}{*}{$\begin{array}{c}\text { Foreign } \\
\text { biological } \\
\text { reagent supplier }\end{array}$} \\
\hline $\mathrm{R} 2$ & $\begin{array}{c}\text { Qualification } \\
\text { risk }\end{array}$ & 60 & & \\
\hline $\mathrm{R} 3$ & Audit risk & 40 & B & $\begin{array}{l}\text { Domestic } \\
\text { demand of } \\
\text { biological } \\
\text { reagent }\end{array}$ \\
\hline $\mathrm{R} 4$ & $\begin{array}{l}\text { Pre approval } \\
\text { risk }\end{array}$ & 70 & $\mathrm{C}$ & $\begin{array}{c}\text { Health } \\
\text { management } \\
\text { department }\end{array}$ \\
\hline R5 & $\begin{array}{l}\text { Regulatory } \\
\text { risk }\end{array}$ & 80 & $\mathrm{D}$ & $\begin{array}{l}\text { Department of } \\
\text { quality } \\
\text { supervision }\end{array}$ \\
\hline R6 & $\begin{array}{l}\text { Inspection } \\
\text { risk }\end{array}$ & 60 & E & customhouse \\
\hline
\end{tabular}

TABLE II. RISK CONDUCTION DIRECTION AND PROBABILITY

\begin{tabular}{|c|c|c|c|}
\hline $\begin{array}{c}\text { Risk } \\
\text { source(R) }\end{array}$ & $\begin{array}{c}\text { Risk } \\
\text { receptor(R) }\end{array}$ & $\begin{array}{c}\text { Risk } \\
\text { conduction } \\
\text { path }\end{array}$ & Probability(P) \\
\hline R1 & R3 & R1-3 & 0.7 \\
\hline R2 & R3 & R2-3 & 0.3 \\
\hline R3 & R4 & R3-4 & 0.5 \\
\hline R3 & R5 & R3-5 & 0.5 \\
\hline R4 & R5 & R4-5 & 0.2 \\
\hline R5 & R6 & R5-6 & 0.3 \\
\hline
\end{tabular}

\section{B. Risk Assessment}

The calculation and assessment adopt risk conduction model and risk assessment method mentioned above. Measure the occurrence probability of every risk factor based on the risk transmission path in Fig .2; Calculate each risk value and adds up all the values in order to get the magnitude of risk each subject; Calculate the lost of risk network circulation based on risk conduction path and add together, then compute the comprehensive risk value of the entered biological reagent circulation risk network.

The probability of the original risk factor R1 and R2 are $\mathrm{P}(1)=0.4$ and $\mathrm{P}(2)=0.6$. There are four risk conduction paths based on Fig .2. The explanation would be displayed as followed:

1) Path One ( $R 1-R 3-R 4-R 5-R 6)$

The original risk source in this path is risk of biological reagent product quality from foreign suppliers. Because the risk type is high risk biological reagent, enter reagent circulation risk conduction path needs to pass Health Administration Departments for pre examination (R4).

Procedures of calculation:

$$
\begin{aligned}
& P 1=\frac{P(1) \times P_{1-3}}{2} \times P_{3-4} \times \frac{P_{4-5}}{2} \times P_{5-6} \times \operatorname{loss}(6)+\frac{P(1) \times P_{1-3}}{2} \\
& \times P_{3-4} \times \frac{P_{4-5}}{2} \times \operatorname{loss}(5)+\frac{P(1) \times P_{1-3}}{2} \times P_{3-4} \times \operatorname{loss}(4) \\
& +\frac{P(1) \times P_{1-3}}{2} \times \operatorname{loss}(3)+p(1) \times \operatorname{loss}(1)=43.186
\end{aligned}
$$

2) Path Two (R1-R3-R5-R6)

The original risk source in this path is risk of biological reagent product quality from foreign suppliers. Because the risk type is low risk biological reagent, entered reagent circulation risk conduction path does not need to pass Health Administration Departments for pre examination (R4).

Procedures of calculation:

$$
\begin{aligned}
& P 2=\frac{P(1) \times P_{1-3}}{2} \times \frac{P_{3-5}}{2} \times P_{5-6} \times \operatorname{loss}(6)+\frac{P(1) \times P_{1-3}}{2} \times \frac{P_{3-5}}{2} \\
& \times \operatorname{loss}(5)+\frac{P(1) \times P_{1-3}}{2} \times \operatorname{loss}(3)+p(1) \times \operatorname{loss}(1)=41.03
\end{aligned}
$$

3) Path Three ( $R 2-R 3-R 4-R 5-R 6)$

The original risk source in this path is qualification risk of foreign supplier. Because the risk type is high risk of biological reagent, entered reagent circulation risk conduction path does not need to pass Health Administration Departments for pre examination (R4).

Procedures of calculation:

$$
\begin{aligned}
& P 3=\frac{P(2) \times P_{2-3}}{2} \times P_{3-4} \times \frac{P_{4-5}}{2} \times P_{5-6} \times \operatorname{loss}(6)+\frac{P(2) \times P_{2-3}}{2} \times P_{3-4} \\
& \times \frac{P_{4-5}}{2} \times \operatorname{loss}(5)+\frac{P(2) \times P_{2-3}}{2} \times P_{3-4} \times \operatorname{loss}(4)+\frac{P(2) \times P_{2-3}}{2} \\
& \times \operatorname{loss}(3)+p(2) \times \operatorname{loss}(2)=43.191
\end{aligned}
$$

4) Path Four ( $R 2-R 3-R 5-R 6)$

The original risk source in this path is foreign supplier's quality risk. Because the risk type is low risk of biological reagent, entered reagent circulation risk conduction path does not need to pass Health Administration Departments for pre examination (R4).

Procedures of calculation:

$$
\begin{aligned}
& P 4=\frac{P(2) \times P_{2-3}}{2} \times \frac{P_{3-5}}{2} \times P_{5-6} \times \operatorname{loss}(6)+\frac{P(2) \times P_{2-3}}{2} \times \frac{P_{3-5}}{2} \times \operatorname{loss}(5) \\
& +\frac{P(2) \times P_{2-3}}{2} \times \operatorname{loss}(3)+p(2) \times \operatorname{loss}(2)=41.805
\end{aligned}
$$


Based on the calculation listed above, the result is presented in the calculation table of risk conduction path.

TABLE III. THE CALCULATION TABLE OF RISK CONDUCTION PATH

\begin{tabular}{|c|c|c|c|}
\hline $\begin{array}{c}\text { Risk } \\
\text { source(R) }\end{array}$ & Risk type(T) & $\begin{array}{c}\text { Risk conduction path } \\
(\mathbf{P})\end{array}$ & $\begin{array}{c}\text { Risk loss } \\
\text { value }\end{array}$ \\
\hline \multirow{2}{*}{$\begin{array}{c}\text { Quality } \\
\text { risk (R1) }\end{array}$} & High risk(H) & $\begin{array}{c}\text { P1: R1-R3-R4- } \\
\text { R5-R6 }\end{array}$ & 43.186 \\
\cline { 2 - 4 } & Low risk(L) & P2: R1-R3-R5-R6 & 41.030 \\
\hline \multirow{2}{*}{$\begin{array}{c}\text { Intelligence } \\
\text { risk (R2) }\end{array}$} & High risk(H) & $\begin{array}{c}\text { P3: R2-R3-R4- } \\
\text { R5-R6 }\end{array}$ & 43.191 \\
\cline { 2 - 4 } & Low risk(L) & P4: R2-R3-R5-R6 & 41.805 \\
\hline
\end{tabular}

\section{A comparative analysis of the results of entered biological reagent circulation risk}

Through the calculation, it can be known that high risk type's risk loss value is higher than the low risk type in the same risk source, so more attention should be paid to ensure the safety of high risk reagents. In the same risk type, risk loss value of qualification risk from foreign suppliers themselves is higher than loss value of biological reagent's quality risk, so the government needs to give a high priority to qualification and reputation of foreign suppliers in order to ensure the safety of the entry of biological reagent.

\section{SUMMARY}

In the study, supply chain management theory is employed and the assessment model for risk conduction of entered biological reagents is established. Then different levels of risks and conduction paths of suppliers with different qualification risks are analyzed. It points out that the magnitude of risk conduction path is able to be calculated on the basis of the probability of risk occurrence and consequence of risks and the essential problems of circulation regulation which deserves more attention have already been put forward.

\section{ACKNOWLEDGMENT}

This paper was funded by the Administrative Committee of Zhongguancun Science Park Foundation and the project group of "Discuss of Import and Export Circulated Supervision Model and Platform Construction for Biological Reagents at Zhongguancun", and supported by Science and Technology Department of Hebei provincel project "Study on port service industry development strategy" (NO. 12457204D-35).

\section{REFERENCES}

[1] Akkermans H, Bogerd P, Vos B.Virtuous and vicious cycles on the road towards international supply chain management $[\mathrm{J}]$. International Journal of Operations and Production Management, 1999, 19(5/6): 566-581.

[2] Jukka H, Vei-Markku Markku T. Risk analysis and assessment in network environments $[\mathrm{J}]$. Intetnational Journal of Product Economics, 2002, 78(1): 45-55

[3] See for instance : Freese W. Schubert D. Safety testing and regulation of genetically engineered foods. Biotechnology and Genetic Engineering Reviews 21. 2004 : 299-324.

[4] Myhr A LTraavik T. The precautionary $\mathrm{pn}_{\circ}$ nciple : scientific uncertainty and omitted research in the context of GMO use and release. JAGE(Journal ofA gncultural and Environmental Ethics). 2002. $15: 73-86$.

[5] Roshan Gaonkar, N. Viswanadham. A conceptual and analytical framework for the management of risk in supply chains[C] //
Proceedings of the 2004 IEEE International Conference on Roboties \& Au-tomation, New Orleans: LA. April 2004: 2699-2701.

[6] Cheng Guoping, Liu Qin. The Study on Chaning for Transmiting Path of the Supply Chain Risk. Value Engineering 2009. 4:1-3.

[7] Liu Qin, Cheng Guoping. The Management of Supply Chain Risk Based on Transmission Mechanism [J]. Logistics Engineering Management. 2009. 31(1): 47-49.

[8] Zhou Yan-ju, Qiu Wan-hua, Wang Zong-run. A Review on Supply Chain Risk Management [J]. Systems Engineering. 2006. 24(3): 17.

[9] Probabilistic risk assessment-procedures guide for NASA managers and practitioners-version 1.1. Prepared for office of safety and mission assurance, NASA Headquarters, Washington, DC 20546; August 2002, http://www.hq.nasa.gov/office.

[10] Leitch, M.,2010. ISO 31000:2009 - The new international standard on risk management. Risk Analysis 30 (6), 887-892

[11] Rosa, E.A., 2010. The logical status of risk - to burnish or to dull. Journal of Risk Research 13 (3), 239-253.

[12] Kaplan S. The words of risk analysis. Risk Analysis 1997;17(4):407-17

[13] TFD(2011) http://www.thefreedictionary.com/exposure

[14] Ezell,Winterfeldt. Probabilistic risk analysis and bioterrorism risk. Biosecurity and Bioterrorism 2009; 7(1):108-10.

[15] Parnelletal., Response to Ezell and von Winterfeldt. Biosecurity and Bioterrorism 2009; 7(1):111-2.

[16] Dubois, D., 2010. Representation, propagation and decision issues in risk analysis under incomplete probabilistic information. Risk Analysis 30, 361-368

[17] Flage, R., Baraldi, P., Ameruso, F., Zio, E., Aven, T., 2009 Handling epistemic uncertainties in fault tree analysis by probabilistic and possibilistic approaches. In: Bris, R., Guedes Soares, C., Martorell, S. (Eds.), Reliability, Risk and Safety: Theory and Applications. Supplement Proceedings of the European Safety and Reliability Conference 2009, ESREL 2009, Prague, Czech Republic, 7-10 September 2009

[18] Wei, S. H., \& Chen, S. M. (2009). A new approach for fuzzy risk analysis based on similarity. Expert Systems with Applications, 36(1), 589-598

[19] Wei, S. H., \& Chen, S. M. (2006). A new similarity measure between generalized fuzzy numbers. In Proceedings of the joint $3 \mathrm{rd}$ international conference on soft computing and intelligent systems and 7 th international symposium on advanced intelligent systems (pp. 315-320), Tokyo, Japan.

[20] Hauptmanns, U. (2009). Different sets of reliability data and success criteria in a probabilistic safety assessment for a plant producing nitroglycol. Journal of Hazardous Materials, 162 , $1322 \mathrm{e} 1329$

[21] Ale, B., Bellamy, L.J., Cooke R., Duyvis, M., Kurowicka, D., Lin, P.H., Morales O.,Roelen, A., Spouge, J., 2009. CATS Final Report. Ministry of Transport and Water Management. <http://www.verkeerenwaterstaat.nl/Images/20092749\%20bijla ge\%201_tcm195-270949.pdf>.

[22] Kirwan, B., Gibson, W.H., Hickling, B., 2008. Human error data collection as a precursor to the development of a human reliability assessment capability in air traffic management. Reliability Engineering \& System Safety 93, 217-233. 